\title{
Education Is Life Itself: Biological Evolution as a Model for Human Learning
}

\author{
Paul Grobstein • Alice Lesnick
}

Published online: 2 December 2011

(C) Springer Science+Business Media, LLC 2011

\begin{abstract}
Schooling often rests uneasily on presumed dichotomies between coverage and inquiry, skill development, and creativity. By drawing on the often underrecognized parallels between biological evolution and human learning, this essay argues that formal education needs and ought not to forego the unconscious exploratory processes of informal learning. Rather than posit as natural the cultural story that formal schooling must prepare students to integrate with given cultures and foreknowable futures, the evolutionary perspective shows that education is better thought of as preparing students to create cultures and to change, and foster change, in relation to unknown futures. The properties that distinguish formal from informal learning - conscious reflection and a degree of collective consensus about what constitutes knowledge at any given time - are, we argue, useful not as ends in themselves, but as tools for maximizing, sharing, and extending unconscious, evolutionary learning. Working with them as such offers a way out of some of education's persistent problems. Two autobiographical case studies provide
\end{abstract}

Professor Paul Grobstein, my collaborator, mentor, colleague, and dear friend, died while the manuscript was under review. Paul's career was literally dedicated to evolution, education, and outreach, and it is great that here this paper reaches an audience to whom it might be of use as well as of interest.

P. Grobstein

Department of Biology, Bryn Mawr College,

Bryn Mawr, PA 19010, USA

e-mail: pgrobste@brynmawr.edu

A. Lesnick $(\square)$

Education Program, Bryn Mawr College,

Bryn Mawr, PA 19010, USA

e-mail: alesnick@brynmawr.edu examples of these evolutionary changes and indicate pathways of inquiry by which to pursue them.

Keywords Reflection · Informal learning · Culture

\section{Introduction}

Education either functions as an instrument which is used to facilitate integration of the younger generation into the logic of the present system and bring about conformity or it becomes "the practice of freedom," the means by which women and men deal critically and creatively with reality and discover how to participate in the transformation of their world.

Shaull (1970), p.34

I believe that education is a process of living and not a preparation for future living.

Dewey (1897), p.78

Teachers and educational scholars are accustomed to dichotomies: between content and process, coverage and inquiry, skill development and individual creativity, and order and disarray. We often deal with such dichotomies by a "some of both" approach, a series of semi-independent balancing acts in which the balance depends on local circumstances and preferences and is often strained. In fact, these dichotomies are all facets of a more general opposition, the one about which Freire (1970) wrote: an opposition between "integration" and "freedom." This essay addresses the possibility that evolutionary theory offers a way to conceive and enact education that doesn't inevitably set integration and freedom in opposition and 
counterbalances the tendency of the human brain to construct binaries.

"In times of change," wrote American social philosopher Eric Hoffer, "learners inherit the Earth, while the learned find themselves beautifully equipped to deal with a world that no longer exists." In this paper, we-a neurobiologist and an education researcher-will argue that the theory and practice of education need to be more fully and explicitly set in the context of "times of change," not as an historical oddity but rather as the norm in interrelated biological, individual, and cultural contexts. Rather than sharply divide life science, social science, and individual experience, contemporary approaches argue for their interdependence in relation to various scales of attention (Davis et al. 2000; Esbjorn-Hargens et al. 2010; Lee 2011; Weil 2004). In the context of such interdependence, Dewey's suggestion that we regard education - formal as well as informal — not as "preparation for future living" but rather as "a process of living" provides a way to transcend the familiar dichotomy between integration and freedom. Rethinking preparation from a position of inquiry not based on the opposition of integration and freedom, we will argue, opens a way out of the problem of teaching toward the past rather than the future, and deepens the warrant for opening our classrooms to worlds beyond (and within) them.

Formal education tends to be dominated by a belief that process, inquiry, creativity, and generative disarray all depend on the prior acquisition of particular bodies of knowledge and skills, demonstrably attained according to particular standards. While educational ideals emphasize creative and critical thinking, independence, and questioning/exploration, these beliefs are frequently frustrated in practice by the countervailing assumption that their realization must await students' mastery of conventional forms and understandings - that learning is essentially a linear progression from integration-oriented goals to freedomoriented ones. Even in the arena of early childhood education, we find increasing focus on the task-oriented work of schooling and less support for play (Hirsh-Pasek et al. 2009). Thus, we hear it said that third graders need to know the states and capitols before they can contribute to a discussion of the pros and cons of democratic systems; college freshmen need to grasp principles of critical theory before they can productively comment on a sophisticated literary text; law students need to master case law conventions before they can comment meaningfully on the moral force of a statute.

We are skeptical of such claims - whether made in the context of traditional formal education, special

\footnotetext{
${ }^{1}$ This quotation is widely attributed to Hoffer but we, the Web, and our college's reference staff are unable to determine its original source.
}

education, or education of disadvantaged studentsbecause they are based on two questionable assumptions. The first of these is that the most responsible way to help people cope with future challenges is through encouraging proficiency in a given and culturally anointed body of knowledge and skills. While this may be true in a world that doesn't change, the world we live in, as Hoffer emphasized, doesn't have this character. There is no assurance that any particular body of knowledge and skills will be the one needed to meet future unpredictable challenges.

The second assumption we question is that an individual's lack of attention to past beliefs or practices necessarily amounts to disrespect for collective, cumulative understanding. (For a popular articulation of this view, see Brooks 2009.) In fact, there is no need to envision the relation between the individual and the group, the present and the past, in such oppositional terms. It is equally possible to acknowledge that individuals enrich communities by virtue of their unique perspectives and critiques, and that these in fact contribute importantly to the cumulative understandings on which we all draw to live. Here, as with the traditional opposition of biology and culture, the division of individual exploration and group knowledge into opposing categories introduces a limiting framework for action and thought.

Just as there are problems with a pedagogy exclusively focused on preparation and integration, so too are there problems with a pedagogy of individual freedom. Creative acts do build on prior social and over-time understandings; people less familiar with common understandings are limited in their potential to make productive use of them. People vary in their appetite and aptitude for change. Hence, the tendency in practice to acknowledge the importance both of preparation and integration, of individual freedom, the often uncomfortable sense of acting in the interests of one at the cost of the other.

For us, Dewey's understanding of education as a process of living - a process of change arising via interrelated phenomena of biology and culture salient in contexts that are both individual and current as well as evolving in groups over time-provides a way to see these apparently conflicting interests as instead necessarily and inextricably intertwined in a mutually supportive way. What is essential is not individual freedom in and of itself, but rather the "practice of freedom" as "the means by which men and women deal critically and creatively with reality and discover how to participate in the transformation of their world" (Shaull 1970, p. 34). Freedom, for education, is freedom to engage with our surroundings, embodied and symbolic. Such engagement is both constrained and open-ended, as we 
will explain further on. Conceiving of education as a process of living also points to directions for changes in educational practice that would help achieve a more coherent, useful, and broadly based picture of education -in the context of, and as a context for, ongoing change - to guide policy and practice. In particular, we suggest that creating and sustaining abundant, flexible connections and exchanges between the classroom and the world outside promises to help people to pursue integration and freedom in tandem, in ways that do not involve sacrifice of either one for the other.

In what follows, we draw on biological evolution as both a foundation and a metaphor, and integrate it with considerations of brain function and of cultural organization, in order to offer a conceptual framework for applying Dewey's notion of education as living to current educational challenges. In an effort both to explain and to give concrete expression to this broader unifying vision of education as living, we describe as well some relevant activities of our own. Our hope is that others may find that the perspective of education as living opens the door to reconsiderations of pedagogical practice at all levels of the educational enterprise and to an ongoing evolutionary process in education itself, one in which existing oppositions and problems become the grist from which new approaches emerge.

\section{Biology, Evolution, and Informal Education}

"We must establish our own path in a universe quite indifferent to our suffering, but offering us maximal freedom to thrive, or fail, in our chosen way."

Gould (1990)

In calling attention to what he thought was an undesirable distinction between education as "preparation for future living" and as "a process of living," Dewey was speaking of human life. Gould was writing about life in a much broader sense, as the evolutionary process from which we and all other organisms derive and in which we are all continuing participants. But "life" in the two different senses is much more closely related than it might seem at first consideration. To people whose work is not rooted in an evolutionary understanding of deep time, it may appear inappropriate to consider the lifetime of individuals within the same framework we use to consider all life, across millennia. Our method, though, is to reconcile apparent oppositions by considering them from a great enough distance that parallels between them not usually discerned come into view. While at one level, differences may appear irreconcilable, at another they become less salient. In the present case, we focus on the parallels between individual human learning and large-scale evolution by framing both as processes of ongoing change. This angle of vision helps us recognize that human formal education depends on unconscious adaptive processes of the kind that power evolutionary change as well as on the conscious, reflective processes more commonly associated with schooling.

This recognition suggests that the purpose of education is to prepare learners to engage creatively both with existing structures and with other structures yet to arise. There is, in the evolutionary process, no sharp distinction between "preparation for living" and "process of living," nor between "integration" and "freedom," or between "survival" and "liberation." Individual organisms come into existence with a set of tools (provided by their genomes) that reflect in part previous experiences ("natural selection") and in part random variation. There is no "optimal" set of tools. The tools available to different organisms (both across species and within a species) are different, and each organism both hones its tools and develops new ones throughout its life. In short, neither individuals nor individual species "prepare" for life and then "live" it. Life both for individuals and species is itself an ongoing process of both living and, in so doing, preparing for future life. While our human characteristics of reflection and acculturation add both possibilities and problems (of which more below), it is important to emphasize that we are biological organisms and share with other organisms the more basic capabilities of life as a process in which there is no clear separation between living and preparing for future life.

Similarly, the binaries of both "integration" and of "freedom," and "survival" and "liberation," are fully entangled in living systems. Interactions with other organisms, both like themselves and different from themselves, are simultaneously constraints and scaffoldings for new directions of exploration. "Integration" and "survival" both promote "freedom" and "liberation," and vice versa. One both survives and integrates by building new forms on existing scaffolds, and without them there would be neither freedom nor liberation. Neither set of apparent opposites can be achieved without the other. In biological systems, whatever an organism finds around itself - the location of a beehive, a child's family-is always simultaneously constraint and opportunity.

What unifies for living organisms and the evolutionary process things that appear conflicting for human beings is the fact that both occur in the context of "real life," and so both their reciprocity and appropriate balances between them occur without any benefit being gained by attempting to distinguish between them, or to give priority to one or the other. So, for 
example, in evolutionary terms, it does not make sense to distinguish learning a survival or vocational skill and learning "for learning's sake." This distinction is a human, cultural story, and depends on certain notions about intention, will, and consciousness. This interpretation, which humans give our experience, is not equally meaningful in all spheres. The exploration of living organisms is invested and open-ended. It is a matter of finding the path by creating it and creating the path by taking it.

An additional important feature of biological evolution is that it works well in a universe that is not only "indifferent" but continually and somewhat unpredictably changing, in part through the activities of living organisms themselves. There is no possibility of effective "preparation for life" independent of life itself (just as there is no setting we experience that exists apart from "life itself") because neither the challenges nor the opportunities for individual living organisms can be adequately anticipated in advance. There is in an unpredictably changing universe no alternative but, as Gould maintains, for living organisms to have "the maximum freedom to thrive, or fail." There can be no recipe for success, nor any prescription other than to respond creatively to what one finds around oneself, using past experiences as a take-off point for future exploration.

We are not, of course, advocating educational practices that fully mimic an "indifferent" and unpredictably changing universe. We recognize and will consider below the significance of reflective thought and of human-created cultures that mediate the perceptions, choices, and aspirations of individuals within the universe. Indeed, a major part of our concern is to outline ways in which reflective processes and culture can be more supportive of creative experimentation, less immediately ruthless in their judgments than an indifferent universe is. We do, though, think that the processes of biological evolution and both- notably more effective than most traditional pedagogical postures in producing a diversity of organisms, including humans, able to cope effectively with their environments-provide some guides to more effective forms of pedagogy in the more exclusively human realm, as well as a foundation on which to build them. In particular, we think that it makes sense to replace the idea of education as "preparation for life" with an alternative of greater reliance on the ability of individuals to be creatively responsive to their surroundings. The evolutionary model suggests we might better think of education as a means of encouraging people to recognize and enhance their own inborn capacities to work at the intersection or balance point of integration and freedom, and to discover for themselves and with others the joys, risks, and payoffs of doing so.
While we argue that formal education should be more like the informal learning processes in which people and other organisms engage throughout our lives, we are not advocating the abandonment of formal education and will turn to its distinctive features below. We are also not heedless of the need for people to make their way in both natural and human cultural worlds that make life challenging. The key point here is that there is no reason why "formal," schooled learning needs to forego the positive features that have arisen in the course of biological evolution as common to both informal human learning and biological evolution. Or better: there is actually no essential reason for such a disjunction; rather, the notion of schooled learning as fundamentally distinct from informal education is born of culture. The disjunction of formal and informal learning is a story humans have told ourselves, and so it is one we are in a position to revise. Here, we provide additional reasons to encourage movement toward a more fluid and dynamic relationship between informal and formal learning.

\section{Formal Education: The Interaction of Unconscious and Reflective Processes within Human Social Structures}

We have suggested a parallel between biological evolution and informal learning processes of the sort humans (and other organisms) engage in all of the time: learning takes place in the context of doing. An elephant does not prepare to become an elephant; a human does not prepare to walk, nor to become a carpenter. An elephant becomes an elephant by starting where it is, by random variation, and by interactions with its environment that encourage some changes and discourage others. A human similarly learns to walk or be a carpenter by walking or being a carpenter. Learning in such cases is simultaneously creative and responsive to the constraints and circumstances of the context around one. All organisms try out ways of doing things, then modify them in accord with the results. What drives the learning process is not a pre-conceived, conscious, discrete goal to be reached in the future but rather an engaged and situated exploration in the present. Learning to be better at a task than one has been in the past is driven by immediate feedback about what works and doesn't work locally.

An additional significant feature of biological evolution and informal learning processes is that both are not only highly effective but also occur largely without thought or reflection. Such unconscious adaptive learning needs to be paid more attention to in the classroom context (Dalke et al. 2007), but its power also challenges us to think more deeply about thinking and about the larger structure of 
formal education itself. What role does reflection play in human life? And why, given the potency of unconscious adaptive learning, do we not emphasize such processes in formal education?

Reflection, we suggest, allows humans to conceive possible futures other than those that would be apparent from adaptive unconscious processes alone, and to make use of those, in addition to local experience and local objectives, to influence behavior. Moreover, such reflection makes it possible to conceive possible futures based on the experiences of many people, rather than those of one person alone. It also allows the intentional juxtaposition of insights from retrospective and prospective analysis as they intersect with present understandings - one's own and others'. For example, many people don't live in contexts where they can acquire facility with a second language. Reflection may suggest the benefit to be gained from such a facility, in which case some form of formal education is necessary. One can make similar arguments about other subjects: in the normal course of day-to-day life, one is unlikely to have experiences that would generate more sophisticated understandings and appreciations of literature, or history, or mathematics, or science. The latter depend on some form of education over and above that of informal and unconscious learning.

From this perspective, formal education is best thought of not as an alternative to informal learning but rather as a supplement to it, an effort to extend the range of what would be achieved by informal and unconscious processes, specifically in relation to the envisionment of possible futures not yet modeled or realized in local experience. That human exploration does include imagining different possible futures means that this exploration, too, both within and among individuals, forms part of the context for adaptive unconscious learning. At the same time, it involves, to one degree or another, conscious reflective as well as social processes creating possibilities, desires, and aspirations beyond those that would be generated unconsciously by any individual, and the use of those to deliberately structure experiences that might not otherwise be had. Formal education neither replaces informal, unconscious learning, nor exhausts the range of conceivable futures; rather, it in turn can be built on in this regard. Both the idea that education is preparation for an anticipated future and that education fosters freedom to create new futures are products of reflective processes, efforts to conceive and implement possible futures and, as such, both are resources to further expand the range of conceivable futures.

Education as "preparation" is uncomfortably close, in Shaull's (1970) words restating Friere's concerns, to facilitating "integration of the younger generation into the logic of the present system and bring[ing] about conformity" (p.34). And yet many of us who would quickly reject an interest in conforming with the status quo find ourselves developing, or at least acquiescing to teach, curricula designed to equip students with what are held to be the specific skills they will need to be successful in particular contexts, academic and sociocultural, in the future contexts.

The problems with such an approach are at least fourfold. The most obvious problem is that "preparationdriven" curricula typically require students to take on faith that the material and experiences they are asked to engage with will at some point be meaningful in their lives even if there is no good reason for them to believe so in the present. To put it differently, the material and experiences make insufficient connection to existing understandings, either unconscious or conscious. The upshot is that many students have difficulty engaging with the material.

The second, related problem, that preparation-driven curricula often have little or no impact on unconscious processing. Materials are presented as abstract processes and ideas, and students are encouraged to master them in the same terms. The upshot is that even students who can be persuaded to take seriously the curriculum as offered can frequently display mastery on examinations, but the impact of the learning experiences is both transient and highly context-dependent: "in one ear and out the other" with little transfer to other classes, much less to other life situations.

Aligning preparation-driven curricula with research on the brain's learning processes (Bransford et al. 2000a, b; Zull 2002) can help as teachers connect material and activities to students' lives and provide "hands on" learning activities so as to engage unconscious as well as conscious processes. While effective to one extent or another, such efforts don't address two remaining problems with preparation-driven curricula and, in light of that, create their own problems: students frequently notice that curricula are designed to get them to a particular place and get impatient with what they see as efforts to disguise this: "Just tell me where I'm supposed to get to, what the answer is."

The third problem is highlighted by students' call to, "just tell me where I'm supposed to get to." While preparation-based curricula may reflect creative reflective thought by educators, they seriously limit thought of this kind by students, even when they purport to foster it. Creative reflective thought by students is too often only encouraged to the extent that it moves them closer to the pre-existing objective and otherwise ignored or actively discouraged. Under these circumstances, students learn to use creative reflective thought to guess what the teacher's or curriculum's objective is, not to create and revise objectives themselves in, and in response to, a changing world.

This in turn relates to the fourth problem with preparation-based curricula, which is that they encourage 
students to believe someone, somewhere knows what is needed to be successful and that if only they master that, their success is assured. In making this observation, we are not insensitive to the reality that social and cultural factors play a role in peoples' lives and that some students have advantages over others in their familiarity with skills that contribute to being successful within the context of any given culture and society; we'll discuss this further in the following section. At the same time, it is important that students not be misled with regard to sociocultural organization or any other aspect of the curriculum by the impression that existing understandings are definitive. To mislead them thus is, again, to discourage in them development of reflective thought for the more general and creative purpose it serves.

The problem here is not formal education in and of itself, not the wish to supplement informal and unconscious learning by using conscious processes to create goals and aspirations that will in turn lead to experiences and understandings that students might otherwise not have had. The problem is instead that, in so doing, adults and others occupying roles of social authority tend to presume that the use of creative conscious processes to create goals and aspirations is exclusively the province and prerogative of the adults or authorities. The consequence is an educational environment that, however unintended, encourages students to see formal education as something distinct from their own lives; to adopt, at best, a passive approach to formal education and, at worst, to disengage from it.

Creative, reflective skills are, like other abilities, best acquired by using them. Formal education should have this as its primary goal and so be structured less to get students to absorb specific content and skills and more to encourage them respond to this-and to everything around them-in ways that can potentially reshape the world(s) in which they find themselves. Content, from this perspective, is not at all irrelevant, but should be chosen with the principal objective of giving students things to engage with and react creatively to. Similarly, the creative, reflective processes of a teacher are not irrelevant but should be seen less as establishing a course objective related to particular understandings and more as informing, together with students, the co-construction of understanding, objectives, and aspirations.

Just as students should feel a sense of exciting, if somewhat unknown, potential in formal education classrooms, so should their teachers. The creative, reflective conscious processes of educators should have as their objective encouraging continuing creative, reflective processes by all concerned. Failing that, formal education will continue to be seen, and responded to, as something different from and less engaging than life itself. Rather than any particular skills imagined to be necessary for some anticipated future, students need skills and experiences for dealing with a future unlikely to be any more predictable than the present has been. To achieve this requires engaging students at all levels of the curriculum not only with past understandings but also with existing problems in the world that require the development of new understandings.

\section{Formal Education: Sociocultural Considerations}

We have developed here argument that learning, not only in informal and unconscious modes but also in more formal and reflective ones, is best thought of not as a process of mastering existing knowledge and understandings but rather as a process of using existing knowledge and understandings to create new ones. From this perspective, the business of education is not to transmit knowledge but rather to enhance inquiry skills, to develop an increased ability to respond adaptively and creatively to whatever challenges and desires might be met, including unknown ones, and so to contribute to the shaping of future lives, both individual and collective. In developing the arguments for this conclusion, we have alluded to sociocultural considerations but have not made them as central to our analysis as many others might be inclined to do. We do not regard sociocultural considerations as insignificant in thinking about education; rather, we think that the argument for education as a process of living developed along other lines can shed new light on the significance of sociocultural dimensions of formal education.

The combination of unconscious and reflective processes gives rise not only to new understandings in individuals but also to collective understandings, understandings shared within and among groups of individuals. Such collective understandings play an important role in education, significantly influencing not only the content of classrooms but also their mode of function as well as the criteria by which their product is evaluated. While it is neither possible nor desirable to eliminate collective understandings as a component of the educational process, collective understandings (like the products of both unconscious and reflective processes in individuals) need to be more clearly seen as a takeoff point for new understandings, both individual and collective, rather than as fixed points from which other aspects of the educational process follow. In this section, we examine some existing and influential collective understandings from this perspective.

We are all, to varying degrees, used to considering education in the context of a social science and psychology literature that accustoms us to imagine development in terms of life stages. Piaget (1926) accustomed us to thinking about cognitive development in terms of a series 
of steps, each of which depends on the completion of prior steps. Maslow (1943) argued - with a force that has deeply entered the conceptual surroundings of these questionsthat people live according to a hierarchy of needs by which provision for basic sustenance and safety is necessary for continued growth and self-development. Kohlberg (1981) charted moral development, the capacity for autonomous discernment following from less sophisticated, more relational forms of discernment. In a parallel way, Bloom (1956) argued that critical thinking follows the more basic abilities to input and output information.

Despite the work of many who have critiqued, refined, and transcended stage theory (Belenky et al. 1986; Bruner 1960; Gilligan 1982; Mezirow 1991; Siegler 2005), it persists in the notion of education as preparation, perhaps owing to the obvious synergy between the ensemble of life stage development perspectives and the notion of preparation: As educators we need to help students complete particular stages so they can get onto the next ones. Certainly, there are differences in the kinds of challenges to which individuals can respond productively, and it can be useful for educators to be aware of developmental trends across populations of individuals. At the same time, there is much more variation in the competencies of individuals of the same age, and much more variation in the developmental patterns by which particular competences are achieved, than is implied by strict life stage development perspectives. Moreover, there is increasing evidence that quite sophisticated cognitive abilities are available at developmental stages much earlier than had been previously believed (Bransford et al. 2000a, b; Siegler 2005). In short, life stage development as a collective understanding is useful but should not be reified or regarded as normative. It should not be taken as a rationale at any educational level for the development of curricula or teaching methods that have as their primary objective preparing students for some imagined next stage of development. To do so is to ignore both substantial individual variation and the existence of capabilities as yet to be discovered. In particular, there is every reason to believe that students at all ages and in all contexts are equipped already to play an adaptive and creative role in their own lives, to respond to education as living rather than as preparation.

The opposition of preparation for life and freedom to explore and transform is a cultural story related to the human need to be successful in culture. Both individuals and cultures would be better off without it. Thus, we are convinced that despite the intensity of current calls otherwise, humans need to use formal education not to help people become successful in particular cultures but rather to help people contribute to changing cultures in ways that make the cultures more successful - because more supportive of diversity and creativity- in the long run. Telling students (explicitly or tacitly) that societies and cultures are fixed entities requiring the acquisition of known skills for their successful negotiation misleads students and inhibits broader social change. All students, "disadvantaged" or otherwise, need the ability to reflect creatively on societies and cultures, to respond to them adaptively, and to conceive and try to implement changes in them. Socially shared stories, whether of "history," "mathematics," or any other field, can be resources to this creative reflection, but they ought never to be its destination. And they ought never eclipse the curiosity of the individual who is the last arbiter of social stories, of shared subjectivity -and without whose responses to local challenges and opportunities human knowledge does not advance.

In arriving at this conviction, we recognize the urgency of survival for individuals and groups not at all well accommodated, and often actively oppressed, by current societies and cultures and by current educational systems. These system must change, must become more socially just and more equitable. Our interest in social justice is as much epistemological as it is political. We need systems of formal education open to the broadest possible range of lives and experiences, not only to assure fairness but in the interest of developing new ideas, ways of thinking, and of living.

In the following section, each of us offers a narrative of our particular experience with blurring the boundaries of formal education by including informal, unconscious (nonreflective) processes within it. We hope that these accounts clarify how our ideas are grounded and worked out in practice, without intending to urge any particular program on others. To do so would contradict our basic premise, which is that change is evolutionary and contextual. Each narrative discusses routes we have taken in opening our classrooms to worlds beyond them. The first, "Science Education as Conversation," connects classroom learning to public experience while the second, "Changing What and Whom Formal Education Recognizes," connects classroom learning to private experience. This spanning of the public sphere of the World Wide Web to the individual sphere of private writing and personal knowledge expresses our sense that formal education needs to interact with multiple worlds, at multiple orders of scale, rather than fix on one.

\section{A Case Study of Education as a Process of Living: Science Education as Conversation}

"At the root of this pedagogical approach is a firm belief in the vertical nature of science: you must master A before moving on to B...Certainly, when it comes to teaching the technicalities...the verticality of 
science is unassailable...But science is much more than its technical details...We must embark on a cultural shift that places science in its rightful place alongside music, art, and literature as an indispensable part of what makes life worth living."

Greene (2008)

As suggested by the physicist Brian Greene, the teaching of science is frequently regarded as a paradigmatic case for education as preparation for life rather than life itself, as a situation in which it is patently obvious that freedom must of necessity be deferred until "integration...into the logic of the present system" has been first achieved. And science is frequently also regarded as a subject matter that can and should be taught free of the social and cultural complexities more commonly recognized as associated with the humanities and social sciences. On the other hand, Greene, like many other scientists, has become concerned that science education in this mode is failing to engage significant numbers of students, not because of failings in the students but rather because of teaching practices themselves. He urges that science be taught so as to take "its rightful place alongside music, art, and literature." What would this mean? Could it be done?

In this section, one of us reflects on 30 years or so of experiences as a college science educator who also works with K-12 teachers and in particular on the related questions of whether science education requires a "preparation for life" rather than "life itself" perspective and whether it can be done perhaps even more effectively embracing rather than being isolated from social and cultural complexities.

The traditional perspective, one that I was born into and reared with, is that science education, at least at more basic levels, is more or less synonymous with textbooks, lectures, and examinations. Over the years, I have found myself progressively moving away from all three and toward forms and processes of learning that are more open to students' and my own evolving interests. At this point, I teach college science courses using a variety of Web resources together with personal experiences (of my own and my students) instead of textbooks, creation of Web projects on topics of individual interest in lieu of examinations, and discussions/conversations (in class and on-line on line) largely in place of lectures. The change was a genuinely evolutionary one, driven not by any general theory but rather by a series of local dissatisfactions, both with myself and with my students, and local responses to them. In hindsight, though, the local changes clearly exhibit a more general pattern.

The first thing to go was textbooks, for two somewhat different but related reasons. One was my frustration with students feeling that textbooks defined the material and objectives of the course, using textbooks as the answer to the question, "What should I know?" The other was a sense that faculty, myself included, were doing something similar, using textbooks as a crutch to avoid having themselves to think about what was (and was not) worth teaching. My somewhat inchoate sense at the time was that there was something wrong with an educational process that proceeded from the presumption that someone else defined in advance (for either students or teachers) what someone had to know, that one ought instead to be teaching people how to think - and determine what knowledge is of worth - for themselves.

The next thing to go was examinations. And I remember quite vividly the events that caused that. I had been moving progressively toward a pedagogical style that encouraged students to approach biology as a work in progress, one that they could best appreciate by drawing on and criticizing their own understandings as well as those of professional biologists, by engaging in biological conversation rather than learning about biology. In this particular year, the course started out very well, with lots of student engagement. And then came the first midterm. I had, of course, tried to make the exam a learning experience, one that required students to be thoughtful rather than to regurgitate information or perspectives. But it was, nonetheless and inevitably, an "examination," a context where students felt, entirely appropriately, that what they had to say was being judged by me, rather than being the continuation of a conversation from which they (and I) could learn. Not at all unreasonably, the students felt betrayed. And I realized that if I was actually serious about science education as conversation, my courses needed to fully reflect that. Examinations were out.

In lieu of examinations, I began experimenting with asking students to write several papers on topics of interest to themselves, and with making those papers publicly available on line, as well as engaging in continuing on-line discussion of material of the course in public online forums. Among other things, this meant that the "content" of the course opened up significantly. Not only public policy issues but also historical, literary, and artistic perspectives became a much more integral part of the course, brought into it by the students as much as by me.

The public character of the work in particular opened up a whole new set of directions for me and my students. Writing on subjects of interest to themselves not only encouraged students to wrestle more directly with biology but made the papers much more interesting for me to read than examinations had ever been and gave me a better sense of how my students were thinking. And the public character of the papers created for students a sense that they were not only students but also teachers, participating in the education of not only themselves, their classmates, and 
me, but others worldwide. Ultimately, it helped both me and my students to better understand what I have come to think of as the central feature of education: a shared process of making sense of the world (or whatever part of it one happens to be teaching and learning about at any given time), one in which existing understandings (personal and collective) are the grist for conceiving new understandings.

What about "lectures"? About "content" and "coverage"? That's still a work in progress. Yes, I still lecture some of the time, but I'm learning more every day about how that (and "content" and "coverage") fit into a science-as-conversation context. I'm learning to use "lectures," together with "content" not as the core of the course but rather as a device to encourage conversation, an offering of observations and interpretations that relate to questions on students' minds rather than things they should/are supposed to know. My courses these days are not defined by or about "content"; they use content to encourage new directions in the ongoing conversations. And that, I've come to understand, speaks to the "coverage" issue as well. We all have some tendency to feel that we are not preparing our students well unless they hear about some particular array of material. My sense is that what's important is not what they hear about but rather what they do with what they hear about. Defining courses by "coverage" is part of a preparation for life rather than a life itself perspective. I don't want to prepare my students for any particular future; life is too unpredictable for that. I want them to gain new sophistication in the skills of living-by living. And not in the world of biology or science alone but rather in the world within which biology and science are embedded, the world which both draws from and gives meaning to biology and science.

I'd like to think all this is a contribution to a cultural shift that places science in its rightful place alongside music, art, and literature as an indispensable part of what makes life worth living. Does it work? Yes, in many ways I think it does. It makes teaching a more rich and satisfying part of my own life, one that contributes to its continual renewal. It positions me as a co-learner, co-inquirer with my students, able to model and share with students my approach to learning. And it does indeed seem to open up possibilities in the minds of many of my students, to engage them more personally and in a more lasting way with science as among, in Brian Greene's terms, "the greatest of all adventure stories."

There is, though, a tradeoff here, one that is particularly important to recognize in the context of this essay. While many students are gratifyingly excited by my courses, others are frustrated. The latter is particularly the case for students who come into my courses knowing where they want to go and expecting help in getting there, students who want to be prepared for particular hurdles they anticipate needing to get across in their futures. No, my courses will not assure that one has assimilated information that one may need for the MCATS. They won't even assure that one has the kind of vocabulary and familiarity with existing work that will give one the appearance of a professional biologist or scientist. They are not about preparing for particular future things that people might want to be prepared for. My students, though, do go on to medical school or graduate school or whatever. Not because they have been prepared for them but rather because they have, by thinking, acquired greater skills in thinking and, by living, have acquired greater skills in living. And the breaking down of walls around my classrooms, so they are about life rather than about just biology or science, is a major contributor to that skill acquisition.

\section{A Second Case Study: Changing What and Whom Formal Education Recognizes}

Schooling tends to be a blessing and a curse. It's wonderful when formal study helps people gain experiences and understandings beyond what daily life in a single body and time affords. But when procedures and hierarchies of formal education dominate, rank, and routinize individual experience, we are in trouble. In response to this trouble, we argue here that it helps to bring informal learning into formal education. Openings to informal learning in settings where it is not expected or valued enable formal education to make more use of processes and activities not usually thought of as part of formal education. They also call attention to cultural (not necessarily educative) processes that distinguish between "formal" and "informal" to begin with.

Having been a teacher of elementary, middle, and high school as well as of adults in a range of settings, I have taught for past 13 years in an educational studies program in a liberal arts college. Our education program guides students to explore, facilitate, and transform teaching and learning within and beyond classrooms (Cohen et al. 2007; Lesnick et al. 2007). My research, like my teaching, focuses on collaborative learning. In this section, I offer two of my experiences with bringing informal learning into formal education - one classroom-centered, and one at and across the boundary of the classroom and the broader institution of the college.

To me, to consider the differences between what is and what could be, and then to reflect on how things are thought of as what is - "reality"- or as what could be - "possibility"-is the work of education. And it is the work of education to reconsider what is and what could be, to change the relation between actuality and possibility. Thus, doing education essentially includes changing it as needed lest the stories it tells isolate people from life itself (Percy 1975). In the classroom, plans and goals are 
necessary but not sufficient. Equally necessary are openings to the unexpected and unknown (Dalke and Lesnick 2011).

Of course, when frameworks of reality and possibility are in play, so too are relationships within and between people and between people and the non-human world. Whose "reality" counts? Whose pays? Whose is eligible for study? Who is the knower? Who needs to be taught? And why are people so often concerned to divide the human world into knowers and taught, winners and losers, when in fact everyone has things to teach and things to learn? As my co-author writes, "We live in a culture in which social status and power is based to a large extent on establishing the validity of one's own dreams by exclusion, by successfully challenging the validity of the dreams of others. To decline to engage in that process is to risk being regarded by many others as weak at best and, at worst, as irrelevant or meaningless" (Grobstein 2010). It has been my hope to help my students respond to one another's contributions as part of working with and building from whatever is offered, rather than as a competitive process of recognition and evaluation.

One way I have sought to open academics to informal learning and to de-center the evaluative objective of schooling is via the use of informal writing to learn in the classroom. To invite students to work from spontaneous, personal writing has been a bass note of my teaching (and of my own practice as a learner) across the span of my career. I had the good fortune to come of age as a teacher during the first flowering of the writing process movement. As a third-grade teacher in the mid-1980s, I learned to invite students to use writing to brainstorm, plan, document, and revise their thinking, not only to report or practice conventions. Once I became a faculty associate of the Institute for Writing and Thinking at Bard College, in the early 1990s, I began leading workshops for undergraduates and for practicing teachers in the uses of informal writing across the curriculum to foster learning, inquiry, and pedagogical community (Vilardi and Chang 2009).

While I have used and recommended specific practices (free writing, focused free writing, process or metacognitive writing, dialogue journals, reading logs, etc.) for various curricular and developmental purposes, this paper offers a more general rationale for informal writing in the context of formal education: It is a conduit for life itself, and for the lives of learners as individuals. It is closer to what writing educator Natalie Goldberg (1990) called, "wild mind," closer to the unconscious, and it allows those who undertake it to make contact and then to work with language of the unconscious and experiences not codified as academic. I have come to think of informal learning as including the mind's experience of words, the ways that words make up important parts of our internal and external landscapes. "Informal learning" thus expands to take in not only interpersonal but also intrapersonal experiences not designed as academic.

Informal writing to learn acts as a two-way bridge between the personal and the public, the known and the new. It is a way of thinking that depends on the individual's contact with and disclosure of his or her experience and language for it. "Wild mind" writing encourages us to see language for experience in a more immediate way. Bringing such writing-enabled thinking into the shared space of the classroom allows personal knowledge and language to come to bear on common learning projects. As learners' experiences become texts for classroom use, we can see that to "do education" is to cause change as well as to be changed. Indeed, as experience is cast as text, change-in the "reality" available for uptake by the individual writer and his/her community of practice - is already occurring. Whether the change has to do with the framing or interpretation of a focal topic, or with a challenge to others' assumptions (including the teacher's), or with a shift in the writer's own sense/story of self, or something else, it creates ripples. Some of these come into direct contact, and conflict, with their surroundings, while others move out to unanticipated encounters.

An important route to growth and development is for people to change their worlds as well as themselves: to experience a relationship of mutual impact between their lives (academic and otherwise) and broader contexts of life. This can be dramatic or explicit and also can be understood as an ongoing part of daily life that we often don't recognize as such. A second project through which I have sought to enable and make visible such change and such relationship is a campus-wide learning exchange I helped conceive and lead, The Empowering Learners Partnership (ELP). Part of Bryn Mawr College's Teaching and Learning Initiative, the ELP pairs college students and "nonacademic" staff members in unique teaching and learning relationships. The goal is for participants to gain access to one another's knowledge and interests (and also to their own) and get to know one another outside of their formal campus roles. The mutual respect of a learning partnership, as well as institutional support afforded staff and students, expresses the founding principle that each partner's contribution is equal and worthy of recognition and that no matter how they are positioned by the institutional division of labor, each is both a giver and a receiver. Staff members at all institutional levels - service/craft, clerical/ technical, and administrative/professional - are active in the ELP, and all students are eligible to participate. The egalitarian basis of the program runs counter to intense hierarchies that often prevail on campus and in the world.

The staff-student pairs work in unique 10-14-week partnerships with financial support from the College (staff participants get two hours paid release time per 
week; students are paid hourly, as well, or are afforded fieldwork credit for selected education courses) and both students and staff get program support from TLI coordinators. A faculty and a student co-coordinator help partners identify a focal subject to teach and a focal learning area that relate to their interests and goals. Participants are encouraged to think of themselves as teachers and learners whatever their formal education is. They meet two hours weekly, one hour for each subject, and track their activities, insights, and questions through several discussion and written venues (including reflective logs, a NING site, and midcourse, program-wide discussions). Student participants meet for an additional hour of reflection each week; staff, students, and faculty collaborate in the program advisory committee. The 75 unique partnerships that have taken place to date have focused on such exchanges as Greek cooking/research skills, woodcarving/email literacy, fresh fish preparation/Biblical diction and syntax, baking/house painting, PowerPoint/Tae Kwon Do, Bulgarian language introduction/ESL, crafts/digital photography, Facilities Overview/Creating a Facebook page, and instructional videos for students about campus facilities.

While time and scheduling pose ongoing challenges to the program, participants have affirmed the new friendship, new understanding, and new knowledge it enables. They also speak of feeling a sense of having increased their value to, and benefits from, the campus community (Lesnick and Cook-Sather 2009; Lesnick 2010; Cook-Sather et al. 2011). When students participate in the ELP to fulfill the fieldwork component of selected education courses, they bring into the classroom a wider lens on institutional life, adult learning, and the differences and commonalities they come to recognize with their partners. They also raise questionsand, and others' awareness- about social class, cross-group communication, and what it takes to be a good facilitator of someone else's learning.

The Empowering Learners Partnership follows some of the same contours as the use of informal writing to foster classroom learning. Both draw experience not already framed as academic into visibility and use within classrooms. Both amplify dimensions of people's lives that academic institutions tend to ignore and silence. Both highlight the distributed nature of knowledge - the fact that everyone, by virtue of being someone, has expertise to contribute to the project of learning. And neither is a ready candidate for evaluation via traditional means.

This is not to say that progress, aspiration, and attainment are irrelevant here. When a student or group of students gains insight and fluency through informal writing and thinking practice, we celebrate. And when, at the end of each semester, ELP participants gather with others in the teaching and learning initiative to share their learning via presentations, we celebrate. And then we go on. "Achievement" is more a matter of sustaining engagement than it is of getting to a preset objective or performance. This is consonant with what Peggy McIntosh (2000) called the "horizontal" quality of life and growth. For even by the most traditional standards, human success is never complete or absolute. The fortune is lost in a market crash; the violin prodigy breaks her hand after playing Carnegie Hall; the writer completes a great novel...and then rises the next morning — or not.

Thought of in this way, progress and achievement are part of the engine of continued life and learning, not their end. They are their own ends insofar as they stimulate and make possible more learning/growth/life. In evolutionary terms, then, "adaptation," or successful adjustment to one's environment, is a byproduct of exploration, of living, rather than its objective. In settings of formal education, the point of trying, striving, and working to achieve is to enrich the scene of achievement, not to guarantee the achiever or the product of achievement.

I arrive at these ideas and activities via processes both deliberative and intuitive and via opportunities both made and found. It is not possible, or, according to this paper, desirable, to codify them. They are, as it were, part of my progress and my adaptation as a teacher and learner. My students are about their own progress and adaptation as individuals engaged with life itself. To the extent that we find ways to progress together, we are usefully changed and mutually informed, in-formed. But our interactions take place in specific contexts where counter-definitions of progress and adaptation are always in play. It takes skill, luck, and stamina to elucidate the conflicts among varying definitions and render that conflict generative for individuals' growth; then there is the problem of conflicts between that growth and the social expectations around the person. I do not see a way to resolve these risks ahead of time. That is what makes them risks. And if educational planning can make provision for risk, we must investigate and experiment with how in ongoing ways. I am thus at once minded to stick with this outlook and to recognize the difficultyconceptual, not procedural — of formally recommending it to others. I recommend it not as a program, but as a platform for further inquiry.

\section{Conclusion}

We hope that this essay has provided some indication of the depth of meaning in Dewey's description of education as a process of living and a greater sense of its relevance for contemporary work in education. Rather than seeing education as a preparation for living, we see it as an 
ongoing process of discovering, creating, rediscovering, and recreating ways of living, both individually and collectively Eldredge and Eldredge (2009). Education is a tool that both derives naturally from that process and that should be deliberately honed to further facilitate it.

Biological evolution, the process by which all living things simultaneously adapt and explore, is not only an apt metaphor for this more integrated and more fluid conception of education but a valuable reminder that humans, like all living organisms, are born with the capacity to integrate and explore in ways that reinforce rather than conflict with one another. And this in turn sets an important context for more reflective thinking about education. It has never been and should never be misunderstood to be a process isolated in particular locations and contexts. Humans continually learn from the entirety of their interactions with each other and their surroundings. And they do so without any thought being given to the matter, by themselves or anyone else.

Conscious and reflective thought needs to be more widely recognized as an adjunct to this unconscious learning rather than something at best distinct from it or, at worst, opposed to it. Conscious and reflective thought is not the only, or even the primary, way the brain learns. It is instead an additional mechanism that enhances the potential to notice problems and conceive new ways to address them. This has significant implications for classroom practice (Dalke and Grobstein 2007; Dalke et al. 2007) but equally important implications for thinking about the nature of formal education itself. In particular, it challenges us to reexamine our conscious understandings of the objectives of formal education and the practices that follow from them, while assuring us that we have the wherewithal to do so productively to conceive new objectives and practices that correct existing problems.

What this means in practice is a number of things that many have argued for on other grounds: more hands-on activity, greater attention to the distinctive needs, abilities, and expressive modes of individuals, greater attention to interpersonal exchange (both among students and between students and teachers), assessment mechanisms that focus on individual progress rather than attainment of fixed goals, and so forth. We think that supporting ongoing exploration of viable forms of living, individually and collectively, provides an overall rubric that encourages this ensemble of practices rather than having to defend each of them separately in more local terms. At least as importantly, "supporting ongoing exploration of effective forms of living" adds to the list the importance of breaking down classroom walls. If we are to help students acquire the skills of becoming better able to participate in the ongoing exploration of forms of life, we need to bring life more fully into the classroom and make the classroom more fully a part of human life.
Acknowledgments Grateful thanks to the following colleagues for critiques of earlier drafts: Rashidah Andrews, Jody Cohen, Alison Cook-Sather, Anne Dalke, Deb Hazen, Howard Lesnick, and XuanShi Lim, and to Dominque DeLeon for tireless editorial assistance.

\section{References}

Belenky M, Tarule J, Goldberger N. Women's ways of knowing. New York: Basic Books; 1986.

Bloom BS, editor. Taxonomy of educational objectives, the classification of educational goals - handbook I: cognitive domain. New York: McKay; 1956.

Bransford JD, Brown AL, Cocking RR, editors. How people learn: brain, mind, experience, and school. Washington: National Academy Press; 2000a.

Bransford JD, Brown AL, Cocking RR. Learning: from speculation to science. In: Bransford JD, Brown AL, Cocking RR, editors. How people learn: brain, mind, experience and school. Washington, D. C.: National Academy Press; 2000b.

Brooks, D. (2009). What life asks of us. New York Times. http://www. nytimes.com/2009/01/27/opinion. Accessed 3 April 2011.

Bruner J. The process of education. Cambridge: Harvard University Press; 1960.

Cohen J, Lesnick A, Himeles D. Temporary anchors, impermanent shelter: can the field of education model a new approach to academic work? J Res Pract. 2007;3:2.

Cook-Sather A, Cohen J, Lesnick A (2011). Students as learners and leaders: toward self-authorship and social change on a college campus. Innovations in Education \& Teaching International (in press).

Dalke A, Grobstein P. Story-telling in (at least) three dimensions: an exploration of teaching reading, writing, and beyond. J Teach Writ. 2007;23(1):91-114.

Dalke A, Lesnick A. Teaching intersections: the surprise of gift-giving and -getting in the cultural commons. J Curric Pedag. 2011;8 (1):75-96.

Dalke AF, Cassidy K, Grobstein P, Blank D. Emergent pedagogy: learning to enjoy the uncontrollable - and make it productive. J Educ Chang. 2007;8(2):111-30.

David B. What life asks of us. New York Times. http://www.nytimes. com/2009/01/27/opinion. Accessed 3 Apr 2011

Davis B, Sumara DJ, Luce-Kapler R. Engaging minds: learning and teaching in a complex world. Mahwah: Erlbaum; 2000.

Dewey J. My pedagogic creed. Sch J. 1897;54:77-80.

Eldredge N, Eldredge G. Lessons from EEO: Toward a Universal Evolutionary Curriculum. Evolution: Education and Outreach. 2009;2(4):643-54.

Esbjorn-Hargens S, Reams J, Gunn O. Integral education: new directions for higher learning. Albany: State University of New York Press; 2010.

Freire P. Pedagogy of the oppressed. London: Continuum International; 1970.

Gilligan C. In a different voice. Cambridge: Harvard University Press; 1982.

Goldberg N. Wild mind: living the writer's life. New York: Random House; 1990.

Gould SJ. Wonderful life: the Burgess Shale and the nature of history. New York: Norton; 1990.

Greene B. Put a little science in your life. New York Times. http:// www.nytimes.com/2008/06/01/opinion. Accessed 17 April 2011.

Grobstein P. (2010). Inception, the Constitution, education, and life itself. http://serendip.brynmawr.edu/exchange/node/7718. Accessed 5 May 2011. 
Hirsh-Pasek K, Golinkoff RM, Berk LE, Singer D. A mandate for playful learning in preschool: presenting the evidence. New York: Oxford University Press; 2009.

Kohlberg L. Essays on moral development, volume I: the philosophy of moral development. San Francisco: Harper \& Row; 1981.

Lee $\mathrm{C}$. The centrality of culture to the scientific study of learning and development: how an ecological framework in education research facilitates civic responsibility. J Lit Res. 2011;43:3-38.

Lesnick A. Teaching and learning in community: staff-student learning partnerships as part of a college education. J Community Engagem Sch. 2010;3:1.

Lesnick A, Cook-Sather A. Building civic capacity and responsibility through a radically inclusive teaching and learning initiative. Innov High Educ. 2009;3:1.

Lesnick A, Cohen J, Cook-Sather A. Working the tensions: constructing educational studies within a liberal arts context. In: Bjork C, Johnston DK, Ross H, editors. Taking teaching seriously: how liberal arts colleges prepare teachers to meet today's educational challenges in school. Boulder: Paradigm; 2007.

Maslow AH. A theory of human motivation. Psychol Rev. 1943;50 (4):370-96.
McIntosh, P. (2000). Feeling like a fraud III: finding authentic ways of coming into conflict. Wellesley College: Stones Center for Research on Women (working paper)

Mezirow J. Transformative dimensions of adult learning. San Francisco: Jossey-Bass; 1991.

Percy, W. The loss of the creature. In: The message in the bottle: how queer man is, how queer language is, and what one has to do with the other. New York, NY: Farrar, Straus, and Giroux; 1975. p. 46-63.

Piaget J. Language and thought of the child. London: Paul Kegan; 1926. original work published 1923.

Shaull, R. Foreward. In: Freire, pedagogy of the oppressed. London: The Continuum International Publishing Group Ltd; 1970. p. 29-34.

Siegler RS. Children's learning. Am Psychol. 2005;60:769-78.

Vilardi T, Chang M. Writing-based teaching: essential practices and enduring questions. Albany: State University of New York Press; 2009.

Weil Z. The power and promise of humane education. Cariola Island: New Society Publishers; 2004.

Zull J. The art of changing the brain: enriching teaching by exploring the biology of learning. Sterling: Stylus Publishing; 2002. 